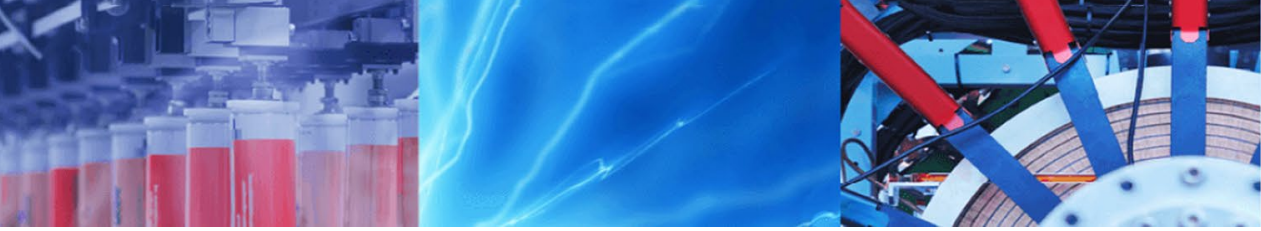

Research Article

\title{
Development and validation of a HPLC-DAD method for quantification of phenolic compounds in different sweet cherry cultivars
}

\author{
Joana Gonçalves ${ }^{1,2} \cdot$ Rodrigo Ramos $^{1} \cdot$ Tiago Rosado $^{1,2} \cdot$ Eugenia Gallardo $^{1,2}$ (D) Ana Paula Duarte ${ }^{1,2}$
}

(c) Springer Nature Switzerland AG 2019

\begin{abstract}
This work describes the validation of a new high-performance liquid chromatography method for the determination of nine phenolic compounds in six cultivars of sweet cherries. Phenolic compounds are a wide and heterogeneous set of secondary metabolites in plants, highly diversified and broadly distributed. These compounds are known for being directly related to many of the health promoting capabilities usually associated to sweet cherries. The samples were submitted to lyophilization, and the process' efficiency varied between 13.21 and $27.13 \%$. The samples were extracted with the extraction directed to phenolic compounds, and the efficiency varied between 78.35 and $98.56 \%$. The high performance liquid chromatography method with a diode array detector was validated, taking into account the guidelines of the Food and Drug Administration. The procedure was considered linear for concentrations ranging from 2 to $50 \mu \mathrm{g} / \mathrm{mL}$, with mean $R^{2}$ value of 0.998 and with precision of the calibrators (mean relative error) within a range of $\pm 15 \%$ except for the lower limit of quantification where the value was $\pm 20 \%$. The herein described procedure was successfully applied for the determination of the studied analytes in six cherry cultivars, demonstrating its usefulness. The compound found in the greatest quantity in the different cultivars was quercetin-3-4'-di-O-glycoside (3.67 $\pm 0.12-132.07 \pm 7.51 \mathrm{mg}$ per $100 \mathrm{~g}$ of fresh fruit).
\end{abstract}

Keywords Prunus avium L. P Phenolic compounds · HPLC-DAD · Methanolic extraction

\section{Introduction}

Phenolic compounds are secondary plant metabolites, being considered one of the most extensive phytochemical groups. These compounds are responsible for a number of food characteristics, namely aspects such as colour, taste, aroma and astringency [8].

There are also multiple health promoting properties associated with this group of compounds. Indeed, it is evidenced that the consumption of phenolic compounds stimulates vasodilation, reduces vascularization and hyperlipidemia, leading to a regression of atherosclerosis $[12,14]$. The risk of thrombosis can also be reduced with the consumption of these compounds, leading to a lower incidence of myocardial infarction, heart disease and ischemia [14]. Phenolic compounds also perform have an important anticancer role $[12,14]$ and reduce the risk of diabetes [1]. In vivo studies have also shown that polyphenols lead to a decrease in lipid peroxidation resulting from the higher activity of antioxidant enzymes (SOD and Gpx) [6].

Sweet cherries are an excellent source of phytochemicals, namely phenolic compounds [6]. Amongst these, flavonoids are the most predominant group, constituting an important part of the diet and being, therefore, the most studied group [5]. Among the flavonoids, anthocyanins

Joana Gonçalves and Rodrigo Ramos have contributed equally to this paper.

Eugenia Gallardo, egallardo@fcsaude.ubi.pt | ${ }^{1}$ Centro de Investigação em Ciências da Saúde (CICS-UBI), Universidade da Beira Interior, Av. Infante D. Henrique, 6201-556 Covilhã, Portugal. ${ }^{2}$ Laboratório de Fármaco-Toxicologia, UBIMedical, Universidade da Beira Interior, EM506, 6201-556 Covilhã, Portugal.

SN Applied Sciences (2019) 1:954 | https://doi.org/10.1007/s42452-019-0680-4

Received: 28 January 2019 / Accepted: 28 May 2019 / Published online: 1 August 2019 
are the most relevant subgroup. The concentration of polyphenols can vary between different sweet cherry cultivars and in different parts thereof [19]. Studies have shown that the antioxidant potential is higher in the stem than in the fruit pulp, leading to the belief that this is due to the higher concentration of phenols also located here [3]. The levels of phenolic compounds can be affected by several factors, and this is associated to both climatic and agronomic conditions $[4,23]$. Ambient temperature, light intensity and type of cultivation are crucial factors that dictate the amount and stability of polyphenols $[6,15]$. The composition of the soil, the type of fertilization and the supply of water and nutrients required by the plant interfere with the nutritional composition of the fruit [6]. Also, the influence of light intensity on the amount of phenols has been described, allowing to conclude that in environments with higher temperatures $\left(25-30^{\circ} \mathrm{C}\right)$ and greater sunlight exposure, anthocyanins and the remaining phenolic content increase significantly $[6,15]$.

Due to their biological properties, interest in the study of phenolic compounds in different sweet cherry cultivars increased substantially. However, the number of reliable analytical methods is limited.

In Portugal, the Fundão region is well known for sweet cherry fruit farms, which are part of the local economy [16]. There are several sweet cherry cultivars, among them Sweetheart, Earlise, Summit, Primulat, Brooks and Saco. It should be noted that Saco is an autochthonous cultivar from the Fundão region and the oldest and most traditional variety [16].

The determination of phenolic compounds was reported in other food matrices as in olive oil [18], using a high performance liquid chromatography coupled to mass spectrometry (HPLC-MS/MS). Another study in acid cherry (Prunus cerasus L.) also allowed the phenolic composition to be determined using a high performance liquid chromatography coupled with fluorescence detection (HPLC-FLD) [20]. A study of several sweet cherry cultivars using high-performance liquid chromatography equipment coupled to ultraviolet (HPLC-UV), diode array (HPLC-DAD) and mass spectrometric (LC-MS) detectors is also described [4]. The sweet cherry (Prunus avium L.) from the region of Fundão, Portugal, has already been studied to quantify melatonin by Rosado et al. [16], applying high performance liquid chromatography coupled with electrochemical detection (HPLC-ECD).

However, HPLC-DAD equipment is one of the simplest and most popular analytical techniques. In addition, the equipment is relatively inexpensive, features easy maintenance [17]. Thus, the present work describes a fast, sensitive and fully validated method to determine polyphenols in six cherry cultivars of the Fundão region using the HPLC coupled to diode array detection technique. The obtained values are compared to others present in the literature and, for the first time the present work reports the levels of the studied compounds in Brooks cultivars.

\section{Materials and methods}

\subsection{Reagents and materials}

The analytical standards quercetin-3,4'-di-O-glycoside, cyanidin-3-O-glycoside and cyanidin ( $\geq 98 \%$ purity grade) were purchased from Extrasynthese (Genay Cedex, France). The remaining standards, namely chlorogenic acid, gallic acid, $p$-coumaric acid, rutin, epicatechin and quercetin were obtained from Sigma-Aldrich (Sintra, Portugal).

Solvents and other reagents used were of analytical grade. Acetonitrile was purchased from Carlo Erba (Italy), methanol was obtained from Fisher Scientific (United Kingdom) and trifluoroacetic acid was purchased from Sigma-Aldrich (Sintra, Portugal). Deionised (DI) water was obtained from a Milli-Q System (Millipore, Billerica, MA, USA).

\subsection{Stock and working solutions}

Individual stock solutions of the analytes were prepared at $1 \mathrm{mg} / \mathrm{mL}$ in methanol. Working solutions were prepared by serial dilutions in methanol. All solutions were stored at $-20^{\circ} \mathrm{C}$ and protected from light.

\subsection{Cherry cultivars specimens}

In the present work, the five cherry cultivars studied from the region of Fundão were Saco, Summit, Sweetheart, Primulat, Brooks e Earlise. These specimens were kindly provided by "Cerfundão-Embalamento e comercialização de cerejas da Cova da Beira, Lda.", and were properly stored at $-20^{\circ} \mathrm{C}$ until analysis.

\subsection{Lyophilization of cherry samples}

Two hundred gram of each cherry sample (fresh or after thawing) was weighed. After weighing, the fruit was frozen at $-80^{\circ} \mathrm{C}$ for at least $24 \mathrm{~h}$ before lyophilization for $60 \mathrm{~h}$. This process was concluded after verifying the almost total loss of water present in the fruit. The freeze-drying yield was calculated according to the following equation:

$\eta=\frac{m_{\text {lyophilized }}}{m_{\text {fresh }}} \times 100$.

\subsection{Extraction of phenolic compounds from cherry}

To each gram of lyophilized fruit was added $20 \mathrm{~mL}$ of methanol acidified with $0.1 \%$ hydrochloric acid. The 
mixture was placed in a thermostatic bath for $2 \mathrm{~h}$ at a temperature of $35^{\circ} \mathrm{C}$ and agitation at $64 \mathrm{rpm}$. This extraction process was repeated twice. Subsequently, the extract was centrifuged for $20 \mathrm{~min}$ at $4000 \mathrm{rpm}$. The solvent was further evaporated under reduced pressure ( $130 \mathrm{mbar}$ ) and at $35^{\circ} \mathrm{C}$ until the dried extract was obtained. The extraction yield was calculated according to the following equation:

$\eta=\frac{m_{\text {extract }}}{m_{\text {lyophilized fruit }}} \times 100$.

\subsection{Instrumental and chromatographic conditions}

The quantification of the phenolic compounds was performed on a high-performance liquid chromatography system (HPLC) 1290 with a binary pump coupled to diode array detector (DAD) from Agilent technologies (Soquímica, Lisboa, Portugal). The compounds were separated with an Eclipse Plus C18 $(3.5 \mu \mathrm{m}, 4.6 \times 100 \mathrm{~mm})$ analytical column from Agilent Technologies (Soquímica, Lisboa, Portugal). Gallic acid and epicatechin were detected at $280 \mathrm{~nm}$, quercetin-3,4'-di-O-glycoside, $p$-coumaric and chlorogenic acids at $320 \mathrm{~nm}$, rutin and quercetin at $360 \mathrm{~nm}$ and, cyanidin and cyanidin-3-O-glycoside at $520 \mathrm{~nm}$. The mobile phase was composed of $0.1 \%$ trifluoroacetic acid in water (A) and acetonitrile (B). A gradient elution system was applied at a flow rate of $0.5 \mathrm{~mL} / \mathrm{min}$. The gradient elution process included $10 \% \mathrm{~A}(0-3 \mathrm{~min}), 15 \% \mathrm{~A}$ (3-15 min), $15 \% \mathrm{~A}(15-20 \mathrm{~min}), 18 \% \mathrm{~A}(20-25 \mathrm{~min})$ and finally $30 \%$ (25-40 min). The injection volume was $20 \mu \mathrm{L}$. The column and sampler temperatures were set to 35 and $4{ }^{\circ} \mathrm{C}$, respectively.

\subsection{Analytical method validation}

The analytical method developed was fully validated according to the guiding principles of the Food and Drug Administration (FDA) [7], which included a 5-day validation protocol and the study of parameters such as selectivity, linearity and limits, intra and inter-day precision and accuracy.

In order to investigate the presence of interferences of the food matrix at the retention times of the phenolic compounds, the selectivity of the analytical method was evaluated. The pure standards of cyanidin, cyanidin-3-glycoside, quercetin, gallic acid, $p$-coumaric acid, rutin, epicatechin, quercetin-3,4'-di-O-glycoside and chlorogenic acid were prepared in methanol at a final concentration of $100 \mu \mathrm{g} /$ $\mathrm{mL}$. The same compounds were injected for determination of the retention time and the wavelength at which absorption was maximum. The method would be considered selective if the analytes did not interfere with each other nor with other matrix constituents.
The linearity of the method was established in the range of $2-50 \mu \mathrm{g} / \mathrm{mL}$ (six calibrators evenly distributed). By tracing the area of the peaks of the phenolic compounds against their concentration, we obtained the calibration curves, and the acceptance criteria included a coefficient of determination $\left(R^{2}\right)$ of at least 0.99 and accuracy of the calibrators within $a \pm 15 \%$ interval, except for the lower limit of quantification (LLOQ), where $\pm 20 \%$ was considered acceptable. Together with each calibration curve, a blank sample and three quality control samples (QC) at concentrations of 4,15 and $40 \mu \mathrm{g} / \mathrm{mL}(\mathrm{n}=3)$ were also analysed. The lowest concentration measured with adequate accuracy and precision, with a coefficient of variation (CV\%) of less than $20 \%$ and a relative error (RE\%) within $\pm 20 \%$ of the nominal concentration was defined as LLOQ. The limit of detection (LOD) was not systematically evaluated, but was assumed to be the same as the LLOQ $(n=5)$. Consequently, values below this value would be considered negative.

Intra-day precision was assessed by analysing in the same day 6 replicates at the concentration levels of 2, 15 and $40 \mu \mathrm{g} / \mathrm{mL}$. Inter-day precision consisted in prepared and analysed samples fortified with the study analytes at concentrations of $2 ; 5 ; 10 ; 20 ; 30$ and $50 \mu \mathrm{g} / \mathrm{mL}$ within the 5 day period. The accuracy of the method was characterized in terms of the mean relative error (RE\%) between the measured and the specified concentrations; the accepted limit was $15 \%$ for all concentrations, except for LLOQ, where $20 \%$ were accepted (Figs. 1, 2).

The carry-over effect was assessed by mobile phase injection immediately after analysis of the highest level calibrator $(50 \mu \mathrm{g} / \mathrm{mL})$.

\section{Results and discussion}

\subsection{Validation of the analytical method}

\subsubsection{Selectivity}

The ability of the analytical method to unequivocally differentiate the mentioned phenolic compounds in the presence of other compounds that exist in the sweet cherry matrix was evaluated. There was no evidence of interference or possible contribution at the retention times of the target compounds, and therefore the method was considered selective.

\subsubsection{Linearity and limits}

The method was considered linear from 2 to $50 \mu \mathrm{g} / \mathrm{mL}$, presenting a $R^{2}$ value between 0.996 and 0.999 , while the accuracy of the calibrators (mean relative error (bias) 

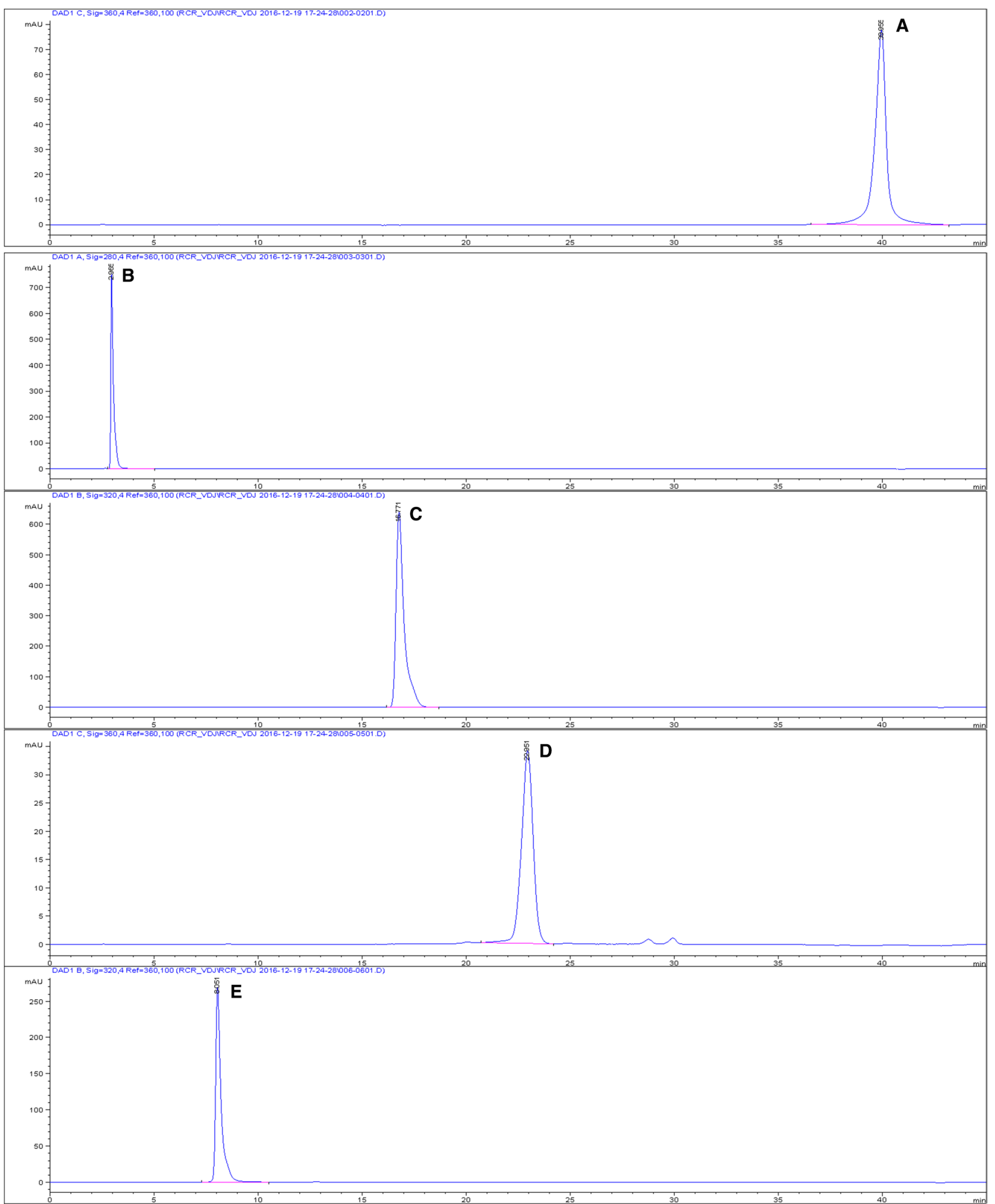

Fig. 1 Chromatograms obtained for quercetin (a), gallic acid (b), p-coumaric acid (c), rutin (d), chlorogenic acid (e), epicatechin (f), cyanidin-3-O-glycoside (g), cyanidin (h), quercetin-3,4'-di-O-glycoside (i), at wavelengths of $280 \mathrm{~nm}, 320 \mathrm{~nm}, 360 \mathrm{~nm}$ and $520 \mathrm{~nm}$ 

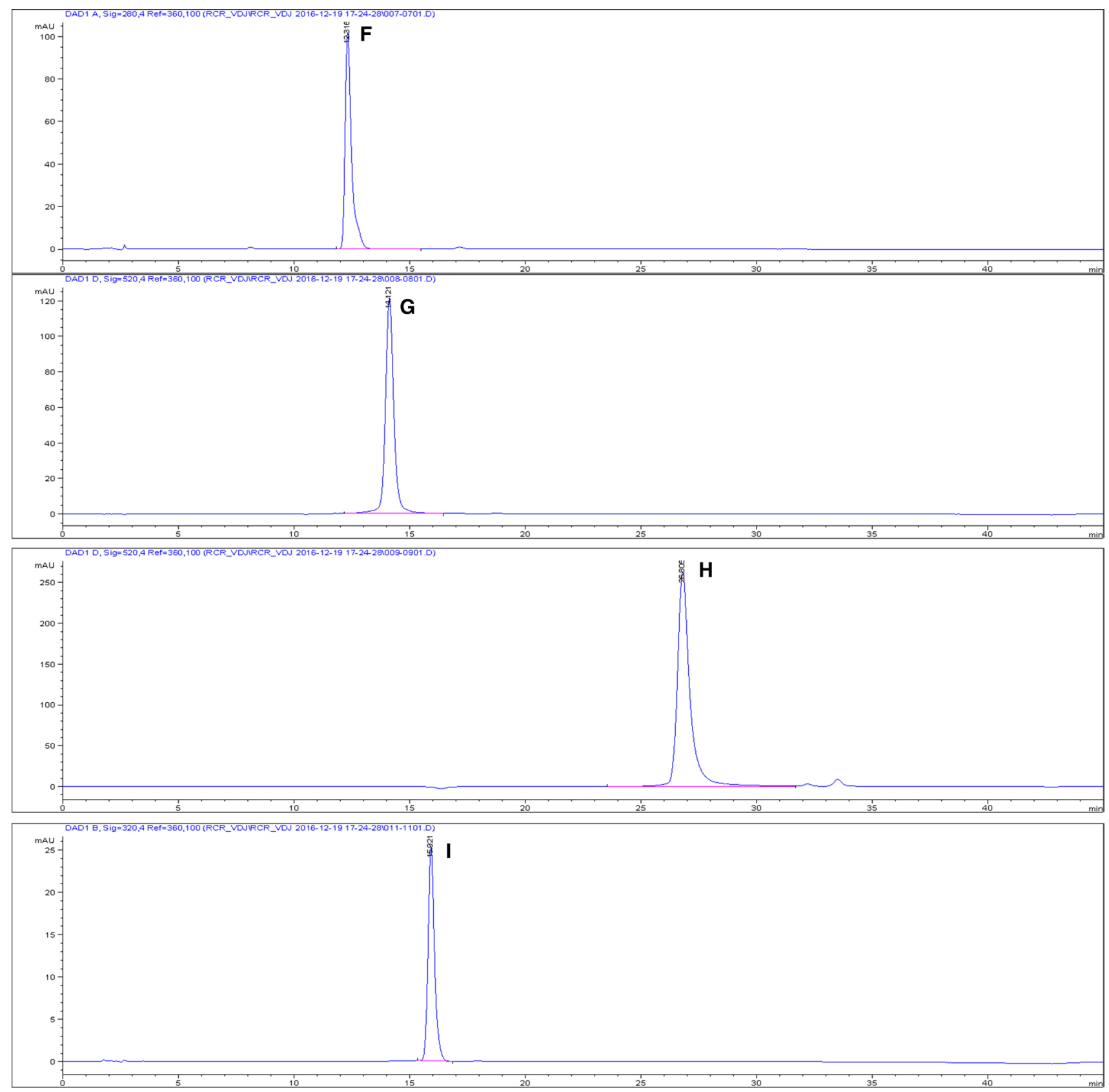

Fig. 1 (continued)

between measured and fortified concentrations) was within a range of $\pm 15 \%$ for all concentrations. Table 1 shows calibration data.

The LLOQ obtained was $2 \mu \mathrm{g} / \mathrm{mL}$. The LOD was not systematically evaluated and was considered the same as the LLOQ.

\subsubsection{Intra- and inter-day precision and accuracy}

Intra-day precision resulted in coefficients of variation (CVs) of less than $8 \%$ at the studied concentration levels, with an average relative error within $\pm 12 \%$. Meanwhile, the assessment of inter-day precision and accuracy 
Fig. 2 Chromatogram of the cultivar Saco at wavelengths $280 \mathrm{~nm}$ [gallic acid (a) and epicatechin (b)], $320 \mathrm{~nm}$ [chlorogenic acid (c), quercetin3,4'-di-O-glycoside (d) and $p$-coumaric acid (e)], $360 \mathrm{~nm}$ [rutin (f) and quercetin (g)] and $520 \mathrm{~nm}$ [cyanidin-3-Oglycoside (h)]
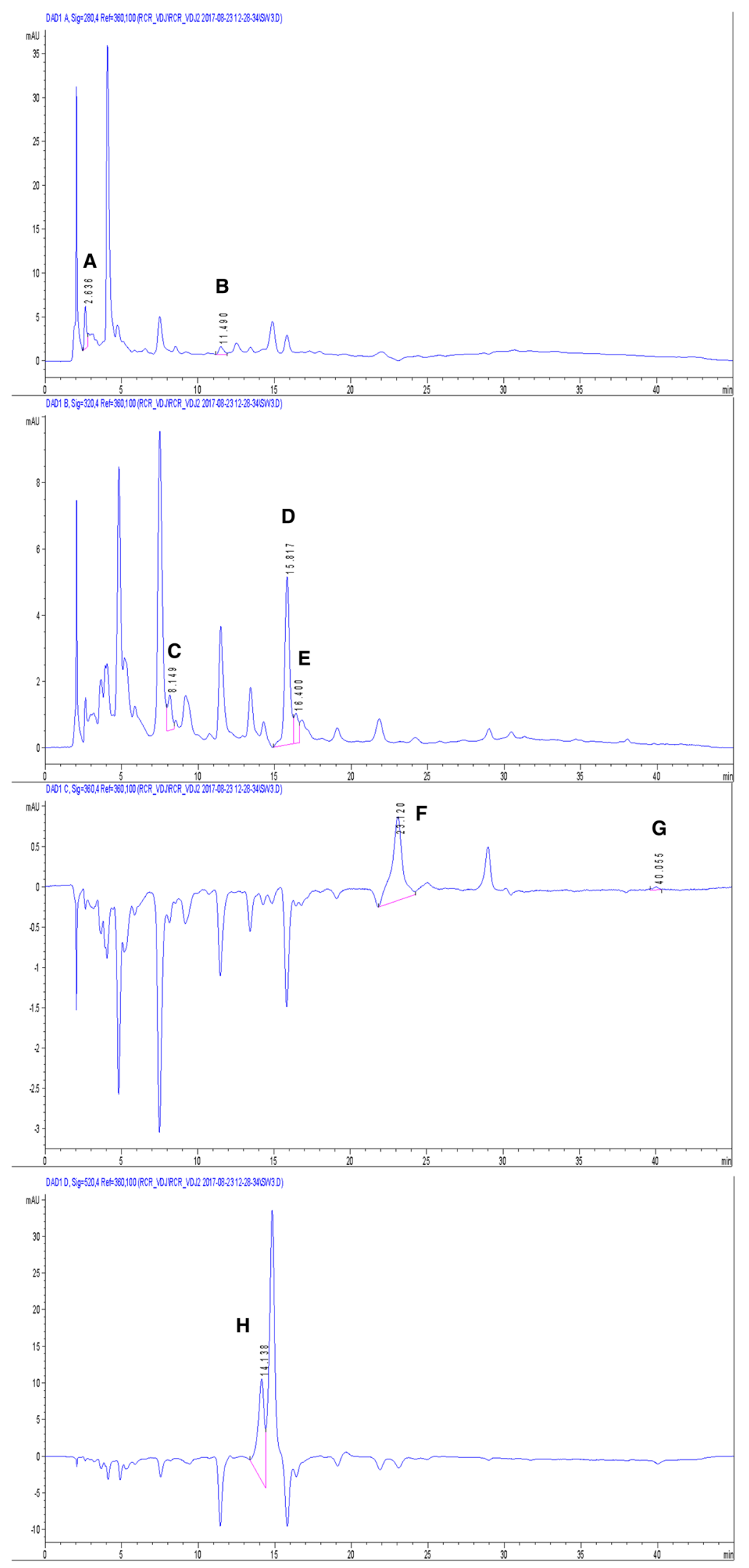
Table 1 Linearity data $(n=5)$

\begin{tabular}{|c|c|c|c|c|c|}
\hline \multirow[t]{2}{*}{ Analytes } & \multirow{2}{*}{$\begin{array}{l}\text { Linear range }(\mu \mathrm{g} / \\
\mathrm{mL})\end{array}$} & \multicolumn{2}{|l|}{ Linearity } & \multirow[t]{2}{*}{$r^{2 a}$} & \multirow[t]{2}{*}{ LLOQ $(\mu \mathrm{g} / \mathrm{mL})$} \\
\hline & & Slope $^{a}$ & Intercept $^{\mathrm{a}}$ & & \\
\hline Gallic acid & $2-50$ & $102.30 \pm 5.27$ & $-18.21 \pm 75.86$ & $0.998 \pm 0.0017$ & 2 \\
\hline$p$-Coumaric acid & & $258.27 \pm 2.23$ & $-270.85 \pm 87.54$ & $0.996 \pm 0.0028$ & \\
\hline Rutin & & $22.78 \pm 1.50$ & $-14.97 \pm 31.13$ & $0.998 \pm 0.0031$ & \\
\hline Chlorogenic acid & & $74.93 \pm 3.29$ & $-83.55 \pm 18.42$ & $0.995 \pm 0.0046$ & \\
\hline Epicatechin & & $26.99 \pm 6.10$ & $-14.87 \pm 16.87$ & $0.998 \pm 0.0003$ & \\
\hline Cyanidin & & $69.01 \pm 0.95$ & $5.69 \pm 11.13$ & $0.998 \pm 0.0019$ & \\
\hline Quercetin-3-4'-di-O-glycoside & & $9.43 \pm 2.75$ & $-7.73 \pm 5.78$ & $0.999 \pm 0.0014$ & \\
\hline Cyanidin-3-O-glycoside & & $46.31 \pm 1.28$ & $-55.74 \pm 36.41$ & $0.999 \pm 0.0013$ & \\
\hline Quercetin & & $44.32 \pm 1.11$ & $-81.25 \pm 37.42$ & $0.998 \pm 0.0017$ & \\
\hline
\end{tabular}

${ }^{\mathrm{a}}$ Mean values $\pm \mathrm{SD}$

resulted in CVs lower than 13\% at all tested concentration levels, with accuracy within $\pm 10 \%$ range. All data are summarized in Table 2.

\subsubsection{Carry over effect}

The possible carry over that could occur and contribute to the signal of the phenolic compounds after the analysis of highly concentrated samples was evaluated. This effect may be caused by contamination of the sample which causes the sample peaks to reappear in subsequent runs and therefore, a blank sample was analysed after the injection of the most concentrated calibrator of the calibration curve $(50 \mu \mathrm{g} / \mathrm{mL})$.

\subsection{Cherry cultivars from region of Fundão, Portugal}

The developed method was used to determine cyanidin, cyanidin-3-glucoside, quercetin, gallic acid, $p$-coumaric acid, rutin, epicatechin, quercetin-3,4'-di-O-glycoside and chlorogenic acid present in six common sweet cherry cultivars from the region of Fundão, Portugal. The cultivars processed and analysed were those of Sweetheart, Earlise, Summit, Primulat, Brooks and Saco.

\subsection{Lyophilization of Prunus avium L. fruit}

The efficiency of lyophilization was determined by comparing fresh weight and lyophilized weight, thus allowing the percentage of water loss to be determined. The results are shown in Table 3.

\subsection{Methanolic extraction of lyophilized fruit of Prunus avium L}

The efficiency of the extraction was determined by comparing the weight of the extract and the weight of lyophilized fruit, thus allowing to determine the effectiveness of the process. The results are shown in Table 3.

One must take into account, however, that other compounds of non-phenolic nature may have been extracted from the lyophilized cherries as well; they were not detected by our selective method, but the values obtained for efficiency may be overestimated.

\subsection{Characterization of the extract of six sweet cherry cultivars from Fundão, Portugal}

The phenolic content of each sweet cherry cultivar was evaluated and is shown in Table 4. For these six cultivars, the absence of quercetin and cyanidin was verified, which is compatible with the literature, although there is at least one study that identifies trace amounts of cyanidin [10]. The cultivar that showed the lowest content of the studied compounds was Earlise, and the results were in accordance to the literature $[9,11,13]$.

Quercetin-3-4'-di-O-glycoside is one of the compounds whose amount varies from $3.67 \pm 0.12 \mathrm{mg} / 100 \mathrm{~g}$ fresh fruit (Earlise) to $132.07 \pm 7.51 \mathrm{mg} / 100 \mathrm{~g}$ of fresh fruit (Primulat). This is the compound that is present at high concentrations. Also cyanidin-3-O-glycoside varies considerably between cultivars. This compound is one of the most frequent in sweet cherries, with a higher content in the cultivar Saco and lower in Earlise.

Rutin, chlorogenic acid and $p$-coumaric acid are common compounds and there are several examples of studies which focus on these compounds in the literature. The sweet cherry cultivars of Fundão have not been the subject of similar studies, however, it was possible to compare 
Table 2 Inter-day and intra-day precision and accuracy

\begin{tabular}{|c|c|c|c|c|c|c|c|}
\hline \multirow[t]{2}{*}{ Analytes } & \multirow{2}{*}{$\begin{array}{l}\text { Concentration } \\
(\mu \mathrm{g} / \mathrm{mL})\end{array}$} & \multicolumn{3}{|l|}{ Inter-day precision } & \multicolumn{3}{|l|}{ Intra-day precision } \\
\hline & & $\begin{array}{l}\text { Calculated Concen- } \\
\text { tration }(\mu \mathrm{g} / \mathrm{mL})\end{array}$ & CV (\%) & RE (\%) & $\begin{array}{l}\text { Calculated Concen- } \\
\text { tration }(\mu \mathrm{g} / \mathrm{mL})\end{array}$ & CV (\%) & RE (\%) \\
\hline \multirow[t]{8}{*}{ Gallic acid } & 2 & 1.60 & 3.75 & -20.15 & 1.61 & 5.59 & -19.57 \\
\hline & 5 & 5.12 & 1.95 & 2.37 & - & - & - \\
\hline & 10 & 10.29 & 1.65 & 2.86 & - & - & - \\
\hline & 15 & - & - & - & 16.37 & 4.76 & 9.11 \\
\hline & 20 & 20.37 & 2.21 & 1.86 & - & - & - \\
\hline & 30 & 29.42 & 4.93 & -1.94 & - & - & - \\
\hline & 40 & - & - & - & 37.78 & 4.82 & -5.54 \\
\hline & 50 & 50.06 & 1.06 & 0.13 & - & - & - \\
\hline \multirow[t]{8}{*}{$p$-Coumaric acid } & 2 & 2.29 & 2.18 & 14.31 & 1.46 & 18.18 & -26.98 \\
\hline & 5 & 5.48 & 4.74 & 9.59 & - & - & - \\
\hline & 10 & 10.07 & 1.59 & 0.74 & - & - & - \\
\hline & 15 & - & - & - & 16.04 & 2.24 & 6.95 \\
\hline & 20 & 19.86 & 0.25 & -0.68 & - & - & - \\
\hline & 30 & 27.65 & 0.69 & -7.83 & - & - & - \\
\hline & 40 & - & - & - & 42.91 & 2.38 & 7.28 \\
\hline & 50 & 50.91 & 1.22 & 1.82 & - & - & - \\
\hline \multirow[t]{8}{*}{ Rutin } & 2 & 1.56 & 3.23 & -22.21 & 1.82 & 6.59 & -9.07 \\
\hline & 5 & 5.36 & 3.73 & 7.30 & - & - & - \\
\hline & 10 & 10.15 & 0.39 & 1.46 & - & - & - \\
\hline & 15 & - & - & - & 15.78 & 2.72 & 5.23 \\
\hline & 20 & 20.25 & 0.35 & 1.24 & - & - & - \\
\hline & 30 & 30.04 & 0.27 & 0.12 & - & - & - \\
\hline & 40 & - & - & - & 39.37 & 3.35 & -1.58 \\
\hline & 50 & 50.34 & 1.13 & 0.68 & - & - & - \\
\hline \multirow[t]{8}{*}{ Chlorogenic acid } & 2 & 2.33 & 2.15 & 16.48 & 1.63 & 7.36 & -18.46 \\
\hline & 5 & 5.65 & 6.02 & 12.96 & - & - & - \\
\hline & 10 & 10.33 & 0.68 & 3.26 & - & - & - \\
\hline & 15 & - & - & - & 15.57 & 2.89 & 3.78 \\
\hline & 20 & 19.63 & 0.71 & -1.87 & - & - & - \\
\hline & 30 & 27.06 & 1.03 & -9.80 & - & - & - \\
\hline & 40 & - & - & - & 39.38 & 5.21 & -1.54 \\
\hline & 50 & 51.24 & 1.42 & 2.47 & - & - & - \\
\hline \multirow[t]{8}{*}{ Epicatechin } & 2 & 2.27 & 0.88 & 13.74 & 2.11 & 8.53 & 5.44 \\
\hline & 5 & 5.69 & 1.76 & 13.87 & - & - & - \\
\hline & 10 & 10.08 & 3.08 & 0.76 & - & - & - \\
\hline & 15 & - & - & - & 14.67 & 9.75 & -2.20 \\
\hline & 20 & 19.07 & 0.37 & -4.66 & - & - & - \\
\hline & 30 & 29.02 & 0.14 & -3.28 & - & - & - \\
\hline & 40 & - & - & - & 36.25 & 3.09 & -9.37 \\
\hline & 50 & 50.87 & 1.04 & 1.73 & - & - & - \\
\hline \multirow[t]{7}{*}{ Cyanidin } & 2 & 1.86 & 3.76 & -6.91 & 1.95 & 1.03 & -2.31 \\
\hline & 5 & 5.00 & 5.00 & 0.06 & - & - & - \\
\hline & 10 & 10.01 & 4.90 & 0.08 & - & - & - \\
\hline & 15 & - & - & - & 14.37 & 5.36 & -4.23 \\
\hline & 20 & 18.84 & 14.49 & -5.81 & - & - & - \\
\hline & 30 & 28.31 & 5.65 & -5.63 & - & - & - \\
\hline & 40 & - & - & - & 41.35 & 4.86 & 3.38 \\
\hline
\end{tabular}


Table 2 (continued)

\begin{tabular}{|c|c|c|c|c|c|c|c|}
\hline \multirow[t]{2}{*}{ Analytes } & \multirow{2}{*}{$\begin{array}{l}\text { Concentration } \\
(\mu \mathrm{g} / \mathrm{mL})\end{array}$} & \multicolumn{3}{|l|}{ Inter-day precision } & \multicolumn{3}{|l|}{ Intra-day precision } \\
\hline & & $\begin{array}{l}\text { Calculated Concen- } \\
\text { tration }(\mu \mathrm{g} / \mathrm{mL})\end{array}$ & CV (\%) & RE (\%) & $\begin{array}{l}\text { Calculated Concen- } \\
\text { tration }(\mu \mathrm{g} / \mathrm{mL})\end{array}$ & CV (\%) & $\mathrm{RE}(\%)$ \\
\hline & 50 & 48.42 & 6.86 & -3.16 & - & - & - \\
\hline \multirow[t]{8}{*}{ Quercetin-3-4'-di-O-glycoside } & 2 & 2.27 & 13.66 & 13.74 & 2.05 & 3.90 & 2.47 \\
\hline & 5 & 5.69 & 8.44 & 13.87 & - & - & - \\
\hline & 10 & 10.08 & 7.64 & 0.76 & - & - & - \\
\hline & 15 & - & - & - & 16.76 & 14.32 & -6.50 \\
\hline & 20 & 19.07 & 6.40 & -4.66 & - & - & - \\
\hline & 30 & 29.02 & 3.31 & -3.28 & - & - & - \\
\hline & 40 & - & - & - & 41.37 & 6.89 & -7.26 \\
\hline & 50 & 50.87 & 1.42 & 1.73 & - & - & - \\
\hline \multirow[t]{8}{*}{ Cyanidin-3-O-glycoside } & 2 & 2.27 & 14.98 & 13.74 & 1.68 & 8.93 & -15.80 \\
\hline & 5 & 5.69 & 4.04 & 13.87 & - & - & - \\
\hline & 10 & 10.08 & 1.69 & 0.76 & - & - & - \\
\hline & 15 & - & - & - & 14.68 & 4.09 & -2.14 \\
\hline & 20 & 19.07 & 3.83 & -4.66 & - & - & - \\
\hline & 30 & 29.02 & 2.07 & -3.28 & - & - & - \\
\hline & 40 & - & - & - & 42.19 & 3.01 & 5.49 \\
\hline & 50 & 50.87 & 0.85 & 1.73 & - & - & - \\
\hline \multirow[t]{8}{*}{ Quercetin } & 2 & 2.21 & 9.05 & 10.57 & 2.23 & 4.48 & 11.32 \\
\hline & 5 & 5.44 & 2.02 & 8.75 & - & - & - \\
\hline & 10 & 9.97 & 1.40 & -0.34 & - & - & - \\
\hline & 15 & - & - & - & 15.25 & 5.44 & 1.66 \\
\hline & 20 & 19.59 & 0.36 & -2.03 & - & - & - \\
\hline & 30 & 29.23 & 1.44 & -2.55 & - & - & - \\
\hline & 40 & - & - & - & 42.13 & 4.30 & 5.32 \\
\hline & 50 & 50.65 & 0.55 & 1.31 & - & - & - \\
\hline
\end{tabular}

Table 3 Efficiency of lyophilization and methanolic extraction of the different sweet cherry cultivars $(n=3)$

\begin{tabular}{lll}
\hline Cultivar & Lyophilization (\%) & Extraction (\%) \\
\hline Saco & 18.39 & 93.89 \\
Primulat & 19.77 & 97.59 \\
Summit & 21.20 & 85.10 \\
Earlise & 13.21 & 78.35 \\
Sweetheart & 27.13 & 98.56 \\
Brooks & 22.53 & 96.98 \\
\hline
\end{tabular}

the Primulat variety with respect to the rutin, chlorogenic acid and epicatechin contents, in relation to the work of Usenik et al. [22].

In the study, it was possible to verify that the determined amounts of rutin, epicatechin and chlorogenic acid were $4.52 \pm 0.19,2.14 \pm 0.16$ and $2.78 \pm 0.02 \mathrm{mg}$ per
100 grams of fresh fruit, respectively. On the other hand, the amounts obtained by Usenik et al. were $2.81 \pm 0.43$, $4.51 \pm 0.00$ and $0.60 \pm 0.06$ [22]. It is known that in the sweet cherry cultivars produced in the Fundão region the amounts of these compounds are considerably higher.

Ballistreri et al. [2] quantified the chlorogenic acid content of Sweetheart cultivar, which was $1.46 \pm 0.10 \mathrm{mg}$ per $100 \mathrm{~g}$ of fresh fruit. By contrast, in the present work the amount of the same compound was $3.94 \pm 0.07 \mathrm{mg}$ per 100 of fresh fruit for the same cultivar.

Another study, published by Serra et al. [19], studied the compounds epicatechin, chlorogenic acid, rutin and cyanidin-3-O-glycoside for the cultivars Saco and Summit, among others. It can be observed that, similarly to the results obtained in our study, the Saco cultivar shows a higher content of phenolic compounds. On the other hand, with the exception of rutin, present in the cultivar Saco, all other components are present in higher quantities.

When comparing the results obtained for sweet cherry cultivars in the Fundão region to those of sweet cherries 
Table 4 Identification and quantification of phenolic compounds in sweet cherry cultivars

\begin{tabular}{lllllll}
\hline Phenolic compound & \multicolumn{5}{l}{ Concentrations $(\mathrm{n}=6)^{\mathrm{a}}$} \\
\cline { 2 - 6 } & Primulat & Summit & Earlise & Sweetheart & Brooks & Saco \\
\hline Quercetin & Not detected & Not detected & Not detected & Not detected & Not detected & Not detected \\
Gallic acid & $0.55 \pm 0.04$ & $0.46 \pm 0.00$ & $0.27 \pm 0.01$ & $0.61 \pm 0.00$ & $0.54 \pm 0.01$ & $0.51 \pm 0.01$ \\
$p$-Coumaric acid & $2.77 \pm 0.03$ & $2.49 \pm 0.01$ & $1.40 \pm 0.01$ & $3.50 \pm 0.00$ & $2.91 \pm 0.02$ & $2.28 \pm 0.01$ \\
Rutin & $4.52 \pm 0.19$ & $4.13 \pm 0.21$ & $3.17 \pm 0.02$ & $7.56 \pm 0.38$ & $5.20 \pm 0.15$ & $10.66 \pm 0.07$ \\
Chlorogenic acid & $2.78 \pm 0.02$ & $3.13 \pm 0.06$ & $2.16 \pm 0.03$ & $3.94 \pm 0.07$ & $3.30 \pm 0.03$ & $2.95 \pm 0.10$ \\
Epicatechin & $2.14 \pm 0.16$ & $2.65 \pm 0.09$ & $0.79 \pm 0.00$ & $4.43 \pm 0.29$ & $3.63 \pm 0.14$ & $1.51 \pm 0.15$ \\
Cyanidin-3-O-glycoside & $12.23 \pm 0.79$ & $3.54 \pm 0.10$ & $1.81 \pm 0.02$ & $4.76 \pm 0.13$ & $4.43 \pm 0.06$ & $22.03 \pm 0.74$ \\
Cyanidin & Not detected & Not detected & Not detected & Not detected & Not detected & Not detected \\
Quercetin-3-4'-di-O-glycoside & $132.07 \pm 7.51$ & $43.54 \pm 1.32$ & $3.67 \pm 0.12$ & $28.31 \pm 4.89$ & $64.59 \pm 1.13$ & $24.61 \pm 0.42$ \\
\hline
\end{tabular}

Concentrations expressed in milligrams per $100 \mathrm{~g}$ of fresh fruit \pm SD

${ }^{\mathrm{a}}$ Mean values $\pm \mathrm{SD}$

from other regions, differences are observed. Tsao et al. [21] quantified phenolic compounds in various fruits, including sweet cherries. It was possible to verify that the compounds present in larger quantities are phenolic acids. By contrast, in the present work, flavonoids are present in greater amounts. These compounds, as already mentioned, have a high number of health benefits. The phenolic acids analysed are found in lower quantities in the sweet cherry cultivars of Fundão.

\section{Conclusions}

An analytical method using a fast extraction and a high performance liquid chromatography coupled to a diode array detector was developed for the simultaneous quantification of nine phenolic compounds in six cultivars of sweet cherries samples. The analytical method was linear in the range of $2-50 \mu \mathrm{g} / \mathrm{mL}$ for the referred compounds. The precision and accuracy were also adequate and LLOQ obtained was $2 \mu \mathrm{g} / \mathrm{mL}$. Concentrations of $0.27-132.07 \mathrm{mg} / 100 \mathrm{~g}$ of fresh fruit were found in the cultivars analysed, where the cultivar Primulat presented the highest levels. In contrast, Earlise showed the lowest concentration of phenolic compounds. The present work reports for the first time the levels of the studied compounds in Brooks cultivars. In addition, this method has a reduced consumption of solvents, is fast and simple, constituting an alternative to traditional extraction techniques.

Acknowledgements The authors acknowledge Eng. Adriano Raposo for his assistance concerning the figures.

Funding This work was funded by FEDER funds through the POCI-COMPETE 2020-Operational Program Competitiveness and
Internationalization in Axis I-Strengthening research, technological development, and innovation (Project POCl-01-0145- FEDER-007491) and National Funds by Fundação para a Ciência e a Tecnologia (Project UID/Multi/00709/2013).

\section{Compliance with ethical standards}

Conflict of interest The authors declare that they have no conflict of interest.

Ethical approval This article does not contain any studies with animals or human participants performed by any of the authors.

\section{References}

1. Acosta-Estrada BA, Gutiérrez-Uribe JA, Serna-Saldívar SO (2014) Bound phenolics in foods, a review. Food Chem 152:46-55. https ://doi.org/10.1016/J.FOODCHEM.2013.11.093

2. Ballistreri G, Continella A, Gentile A et al (2013) Fruit quality and bioactive compounds relevant to human health of sweet cherry (Prunus avium L.) cultivars grown in Italy. Food Chem 140:630638. https://doi.org/10.1016/J.FOODCHEM.2012.11.024

3. Bastos C, Barros L, Dueñas M et al (2015) Chemical characterisation and bioactive properties of Prunus avium L.: the widely studied fruits and the unexplored stems. Food Chem 173:10451053. https://doi.org/10.1016/J.FOODCHEM.2014.10.145

4. Commisso M, Bianconi M, DiCarlo F et al (2017) Multi-approach metabolomics analysis and artificial simplified phytocomplexes reveal cultivar-dependent synergy between polyphenols and ascorbic acid in fruits of the sweet cherry (Prunus avium L.). PLoS ONE 12:e0180889. https://doi.org/10.1371/journal.pone.0180889

5. Del Rio D, Costa LG, Lean MEJ, Crozier A (2010) Polyphenols and health: what compounds are involved? Nutr Metab Cardiovasc Dis 20:1-6. https://doi.org/10.1016/j.numecd.2009.05.015

6. Ferretti G, Bacchetti T, Belleggia A, Neri D (2010) Cherry antioxidants: from farm to table. Molecules 15:6993-7005. https://doi. org/10.3390/molecules 15106993

7. Food and Drug Administration (2018) Bioanalytical method validation guidance for industry. http://www.fda.gov/Drugs/Guida nceComplianceRegulatoryInformation/Guidances/default.htm. Accessed 26 Jun 2018

\section{SN Applied Sciences}


8. Giada MLR (2013) Food phenolic compounds: main classes, sources and their antioxidant power. In: Oxidative stress and chronic degenerative diseases - a role for antioxidants, InTech, pp 87-112

9. Gil-Izquierdo A, Zafrilla P, Tomás-Barberán FA (2002) An in vitro method to simulate phenolic compound release from the food matrix in the gastrointestinal tract. Eur Food Res Technol 214:155-159. https://doi.org/10.1007/s00217-001-0428-3

10. González-Gómez D, Lozano M, Fernández-León MF, Bernalte MJ, Ayuso MC, Rodríguez AB (2010) Sweet cherry phytochemicals: identification and characterization by HPLC-DAD/ESI-MS in six sweet-cherry cultivars grown in Valle del Jerte (Spain). Academic Press, Oxford

11. Grigoras CG, Destandau E, Zubrzycki S, Elfakir C (2012) Sweet cherries anthocyanins: an environmental friendly extraction and purification method. Sep Purif Technol 100:51-58. https://doi. org/10.1016/J.SEPPUR.2012.08.032

12. Haminiuk CWI, Maciel GM, Plata-Oviedo MSV, Peralta RM (2012) Phenolic compounds in fruits-an overview. Int J Food Sci Technol 47:2023-2044. https://doi.org/10.111 1/j.1365-2621.2012.03067.x

13. Kelebek H, Selli S (2011) Evaluation of chemical constituents and antioxidant activity of sweet cherry (Prunus avium L.) cultivars. Int J Food Sci Technol 46:2530-2537. https://doi.org/10.1 $111 / \mathrm{j} .1365-2621.2011 .02777 . x$

14. Li A-N, Li S, Zhang Y-J et al (2014) Resources and biological activities of natural polyphenols. Nutrients 6:6020-6047. https://doi. org/10.3390/nu6126020

15. McCune LM, Kubota C, Stendell-Hollis NR, Thomson CA (2010) Cherries and health: a review. Crit Rev Food Sci Nutr 51:1-12. https://doi.org/10.1080/10408390903001719

16. Rosado T, Henriques I, Gallardo E, Duarte AP (2017) Determination of melatonin levels in different cherry cultivars by highperformance liquid chromatography coupled to electrochemical detection. Eur Food Res Technol 243:1749-1757. https://doi. org/10.1007/s00217-017-2880-8

17. Rosado T, Soares S, Malaca $S$ et al (2018) The role of liquid chromatography in toxicological analysis. In: Lucero I (ed)
High-performance liquid chromatography: ypes, parameters and applications, 1st edn. Nova Science Publishers Inc, Hauppauge, pp 1-120

18. Rubió L, Macià A, Castell-Auví A et al (2014) Effect of the cooccurring olive oil and thyme extracts on the phenolic bioaccesibility and bioavailability assessed by in vitro digestion and cell models. Food Chem 149:277-284. https://doi.org/10.1016/J. FOODCHEM.2013.10.075

19. Serra AT, Duarte RO, Bronze MR, Duarte CMM (2011) Identification of bioactive response in traditional cherries from Portugal. Food Chem 125:318-325. https://doi.org/10.1016/J.FOODC HEM.2010.07.088

20. Toydemir G, Boyacioglu D, Capanoglu E et al (2013) Investigating the transport dynamics of anthocyanins from unprocessed fruit and processed fruit juice from sour cherry (Prunus cerasus L.) across Intestinal epithelial cells. J Agric Food Chem 61:1143411441. https://doi.org/10.1021/jf4032519

21. Tsao R, Yang R (2003) Optimization of a new mobile phase to know the complex and real polyphenolic composition: towards a total phenolic index using high-performance liquid chromatography. J Chromatogr A 1018:29-40. https://doi. org/10.1016/J.CHROMA.2003.08.034

22. Usenik V, Fabčič J, Štampar F (2008) Sugars, organic acids, phenolic composition and antioxidant activity of sweet cherry (Prunus avium L.). Food Chem 107:185-192. https://doi. org/10.1016/J.FOODCHEM.2007.08.004

23. Wang $M$, Jiang N, Wang $Y$ et al (2017) Characterization of phenolic compounds from early and late ripening sweet cherries and their antioxidant and antifungal activities. J Agric Food Chem 65:5413-5420. https://doi.org/10.1021/acs.jafc.7b01409

Publisher's Note Springer Nature remains neutral with regard to jurisdictional claims in published maps and institutional affiliations. 